\title{
La publicidad social en México, comprender su pasado y crear su futuro
}

\author{
Eder Antonio Salamanca Fuentes \\ Liliana Andrea Sánchez Islas \\ Universidad Nacional Autónoma de México
}

\begin{abstract}
Resumen
El objetivo de la publicidad social es primordialmente un cambio de comportamiento o actitud para el bienestar social; por lo tanto, en este trabajo consideramos de gran interés, revisar el desarrollo histórico que ha tenido esta forma de publicidad en México desde el régimen de Lázaro Cárdenas (19341940) hasta la actualidad, para mostrar los cambios que han presentado las campañas de publicidad social, sus causas, agentes de cambio, destinatarios y canales. El resultado del análisis, demostró la evolución de la publicidad social en México y los aspectos que se relacionan con el desarrollo político y económico en el país, desde objetivos ideológicos y problemas sociales locales, hasta crisis globales y medios digitales.
\end{abstract}

Palabras-clave:

Publicidad social. Historia. Evolución. México.

\section{Cambiando comportamientos ${ }^{1}$}

De acuerdo con los pioneros de esta estrategia, la publicidad social es "un esfuerzo organizado, dirigido por un grupo (el agente de cambio) que intenta persuadir a otros (los adoptantes) con el objetivo de que acepten, modifiquen o abandonen ciertas ideas, actitudes, prácticas y conductas" (KOTLER \& ROBERTO, 1993, p.7). También es llamada publicidad de causas sociales o publicidad de bien público, la cual parte de productos sociales intangibles cuyo impacto en la sociedad se puede ver reflejado a corto, mediano y largo plazo. Su finalidad es servir a estas causas, entendiendo las circunstancias y condiciones sociales en las que las personas nacen, crecen, viven, se desarrollan y envejecen.

La complejidad de las campañas de publicidad social, a diferencia de las campañas de índole comercial, radica en estudiar los valores de los sujetos en un contexto determinado para realizar, de ser necesario, una reconversión de los mismos o inculcar

1 Esta investigación fue presentada en el XIV Congreso de la Asociación Latinoamericana de Investigadores de la Comunicación (ALAIC) realizado em San José, Costa Rica, 30, 31 de julio y 1 de agosto 2018.

Revista Ícone (ISSN 2175-215X) • DOI: 10.34176/icone.v17i2.241356

Recife, Vol. 17, N. 2, 213-228, ○ 2019 PPGCOM/UFPE.

Artigo recebido em 29 dez. 2018 e aprovado em 14 mai. 2019.

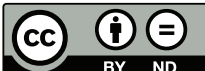


valores nuevos o emergentes, más que hacer un cambio radical o sustituir los tradicionales o emergentes. "El desafío de la comunicación social es a menudo el de crear comportamientos completamente nuevos. En vez de captar al consumidor del competidor, las campañas de bien público enfrentan a un "competidor" representado bajo la forma de "no hacer nada" o "hacer lo que hace siempre" (GANDOLFO, 2012, p. 62). Puede que el público objetivo o adoptante, acepte de manera positiva los mensajes, pero si no se refuerza con otras acciones educativas y preventivas, es probable que no se genere un cambio.

Las campañas de publicidad social pueden clasificarse en nueve tipos acorde a los objetivos a alcanzar en las causas sociales que se pretendan abordar:

1. Campañas de imagen.- Inducen una favorable percepción general de la organización, de sus fines y de su actuación con el objeto de conseguir una disposición positiva por parte del público al que va dirigido.

2. Campañas de información.- Dan a conocer, situaciones, problemas, asuntos de interés público o social. El problema fundamental es crear conocimiento de determinadas situaciones o problemas sociales.

3. Campañas de atención.- Brindan apoyo y/o acompañamiento a personas con algún padecimiento físico y/o emocional, en situación de crisis o víctimas de algún tipo de violencia.

4. Campañas de prevención.- Promueven hábitos que ayuden a evitar prácticas de riesgo en grupos vulnerables. El objetivo es generar conciencia de las consecuencias de realizar acciones que sean nocivas para su persona.

5. Campañas de incentivación a la acción inmediata.- Consiguen una reacción inmediata del público. Se busca persuadir al público destinatario a realizar una acción comprendida en un periodo de tiempo específico.

6. Campañas de sensibilización.- Logran efectos en los sentimientos y creencias de las personas, incentivando o creando una actitud nueva y provechosa para la comunidad a quien va dirigida la campaña. No pretenden modificar valores o conductas de manera profunda, simplemente buscan una respuesta favorable mediante mensajes dirigidos al lado sentimental del ser humano.

7. Campañas de alteración de creencias.- Promueven la adopción de creencias y valores o su actualización y modificación. Cabe hacer hincapié, que este tipo de campañas tienen escaso alcance y los efectos de respuesta son lentos ya que las personas no suelen modificar fácilmente sus propias convicciones y valores.

8. Campañas de promoción en la participación de actividades de responsabilidad cívica.- Promueven en el ciudadano el interés por participar de forma activa en actos cívicos que buscan colaborar en la construcción del país

9. Campañas de solicitud de apoyo a la sociedad frente a las contingencias naturales.- Responden a circunstancias específicas de desastre, en las que por alguna razón, la población mexicana necesitan contar con el auxilio de otros Estados. 


\section{Recopilando los esfuerzos}

Un antecedente esencial para el desarrollo de la publicidad social en México fue la creación durante el régimen del presidente Lázaro Cárdenas (1934-1940) del Departamento Autónomo de Publicidad y Propaganda, mejor conocido como el DAPP. La publicidad creada durante este periodo, pese a ser realizada y difundida por el Gobierno, contaba con los elementos que caracterizan a la publicidad social. Sus esferas de acción se limitan a la Publicidad y a la Propaganda, entendida la primera no como la esfera de lo mercantil, sino la del ámbito público.

El criterio del entonces presidente para afianzar su proyecto de Estado se basó en estrategias de comunicación, bajo la perspectiva de movilización social y la información, fue formulado en términos de incorporar a "todos los sectores sociales" del país.

El DAPP se encarga entre otros asuntos de informar oficialmente a la prensa de las actividades de las diversas dependencias del Ejecutivo. Esta labor requiere de toda una organización cuya estructura interna está integrada por seis oficinas, además de la administración del Archivo General de la Nación. (González Marín, 2006, pág. 121)

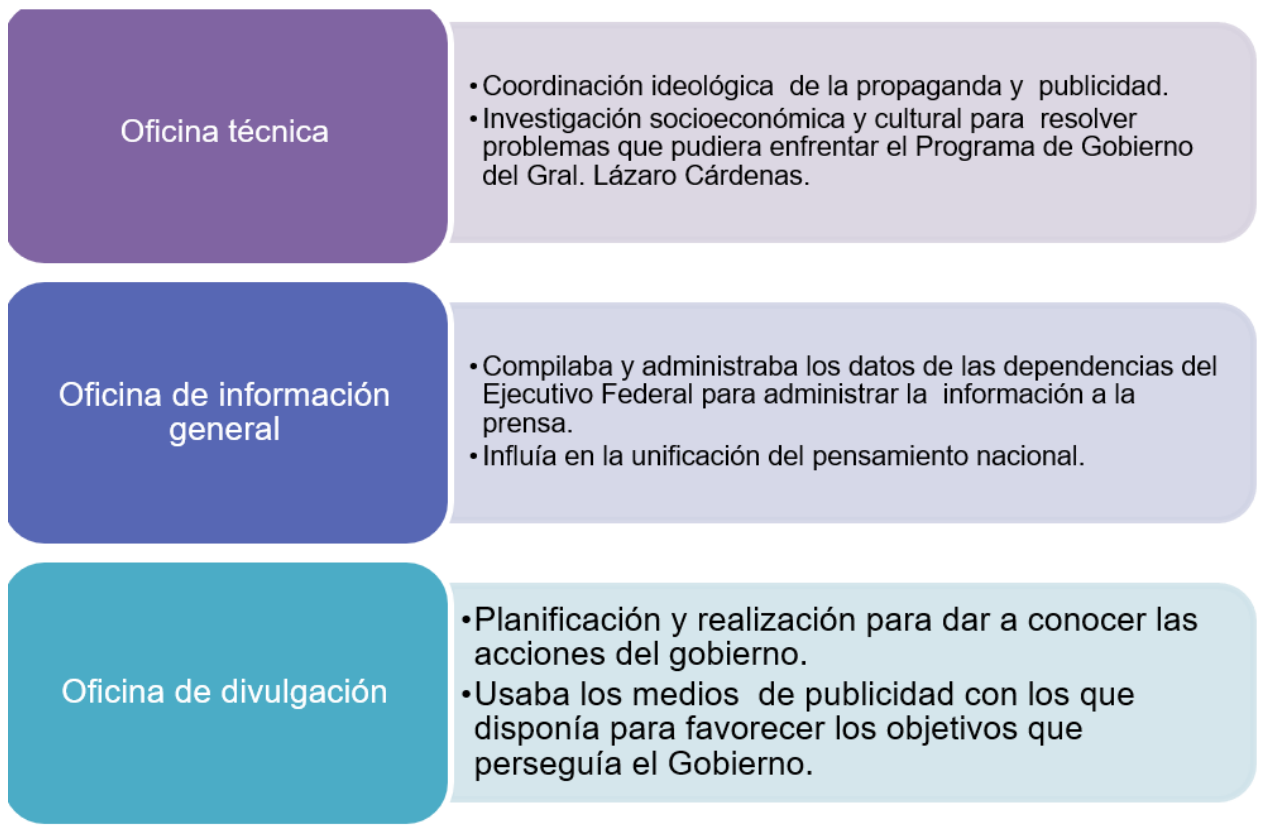

Figura 1 - Organización del Departamento de Departamento Autónomo de Publicidad y Propaganda. Elaboración propia con información obtenida del la Memoria del Departamento de Departamento Autónomo de Publicidad y Propaganda (1938). 
El Departamento de Departamento Autónomo de Publicidad y Propaganda contaba con una estructura muy precisa de comunicación. Ver Figura 1.

En este periodo el Departamento realizó un análisis y ubicó las problemáticas que amenazaban el desarrollo del programa Cardenista, consolidó este organismo para realizar un convencimiento para modificar estas conductas. Consideraremos por tanto a la DAPP como el agente de cambio de esta época, sus campañas buscaban la prevención y modificación de ciertas actitudes: prevención de enfermedades, cuidado ambiental, educación cívica, prevención de accidentes de trabajo, salubridad e higiene, contra el alcoholismo y fomento de solidaridad social. Los medios utilizados fueron: radio, cinematografía, teatro, carteles, cartulinas, volantes, folletos, mantas, y la distribución de las publicaciones que editaba.

Al desaparecer el DAPP fue la Asociación Nacional de la Publicidad (ANP) el gremio más importante de publicistas, medios y anunciantes, en 1948 se constituyó legalmente y, después de la Segunda Guerra Mundial, se dio a la tarea de impulsar el adelanto económico de México, otros temas de sus campañas se enfocaban principalmente a prevenir y controlar problemas de salud como la epidemia de fiebre aftosa

Otro actor publicitario que hace contrapeso a la ANP fue la Asociación Mexicana de Agencias de la Publicidad (AMAP) creada en 1950, y posteriormente se suma el Consejo Nacional de la Publicidad (CNP).

El CNP se perfilaba como un nuevo promotor de la voz empresarial concentrado en el común de la sociedad, alternativo a las demás confederaciones, cámaras y asociaciones (Excelsior, 1959). Se encargó de difundir campañas de publicidad social. La producción de publicidad social era incipiente y sus alcances aún no eran estudiados del todo, pero ello no limitó a que continuara su camino hasta consolidarse en México a través del Consejo Nacional de la Publicidad, actualmente Consejo de la Comunicación, que a lo largo de más de cuarenta años ha creado decenas de campañas sociales.

Por lo antes expuesto, consideraremos al CNP, entre 1959 al 2000, como el principal agente de cambio de este periodo. El Consejo realizó 49 campañas que se clasificaron en los siguientes rubros: campañas cívicas para promover el voto, restauración y mantenimiento de escuelas, del cuidado del agua, el ahorro de la energía eléctrica y en general el medio ambiente. Destacan las campañas orientadas al beneficio de México, apoyo a otros programas de gobierno con temas de: censos de población y económicos, sector turístico, planificación familiar, superación personal, desarrollo y bienestar de individuo y la familia, fortaleza de México ante el exterior, cuidado del medio ambiente, integración familiar y contra el consumo de drogas Las campañas de apoyo a políticas económicas y a la libre empresa, se orientan a la promoción de la producción, a valorar el trabajo de la iniciativa privada y el apoyo a políticas de gobierno como fueron los programas de Solidaridad Económica y el Tratado de Libre Comercio.

A finales del año 2000, se concretó la reforma da sus estatutos, el Consejo Nacional de la Publicidad cambia de nombre a Consejo de la Comunicación, "para ser más incluyente, invitando a participar a todo aquel que pueda comunicar, y que resulte más adecuado para el enfoque predominante de mercadotecnia social - esto es, 
la búsqueda de cambio de conductas en los individuos- que adquiere la Institución" (CNP, 2001, pág. 90).

Ya como Consejo de la Comunicación destacan como agente de cambio retomado en sus campañas temas que, a su consideración, son de particular relevancia: mejorar la conducta cívica, cambiar la percepción de la honestidad, motivar una mejora colectiva en la calidad, promover valores familiares (visión católica y tradicional de la familia, promoción del voto, fomento a la lectura y fomento de una cultura emprendedora y empresarial.

Otros organismos que recurren al uso de la publicidad social como una herramienta para modificar actitudes son las Organizaciones No Gubernamentales (ONG) creadas por la sociedad civil. Éstas encuentran en la publicidad social la forma idónea de darse a conocer, difundir información, crear conciencia e intentar modificar actitudes. Los temas son muy diversos al igual que los objetivos.

Debido a la diversidad de acciones de estos organismo Korten (1990) citado por (Torres, 1998) las clasifica como: ONG's de primera, segunda y tercera generación considerando la características recopiladas en la Figura 2.

El rápido ascenso de la sociedad civil, que inició en 1985, contextualizada por una crisis, se orientó a incidir en dos perspectivas nacionales: una reforma política y un proyecto económico nacional incluyente. Para 1994 en México se contabilizaron aproximadamente 1325 organizaciones civiles u ONG’s que actuaban en el país, entre ellas organizaciones de: asistencia, promoción social, vivienda, derechos humanos, democracia, asesoría legal, mujeres, indígenas, migrantes, refugiados, derechos humanos ecología, etc. (REYGADAS ROBLES, 1998)

Las ONGs fueron, en los noventa y década de los años 2000, un agente de cambio en México que generaron diversas campañas de acuerdo con el contexto socioeconómico y político. Los temas retomados van desde la prevención al abuso sexual infantil, apoyar a los niños de calle, evitar la violencia familiar, prevención de la drogadicción hasta búsqueda de desaparecidos, protección de los periodistas, protección de los derechos humanos, apoyo a los migrantes etc. Los medios primordialmente,
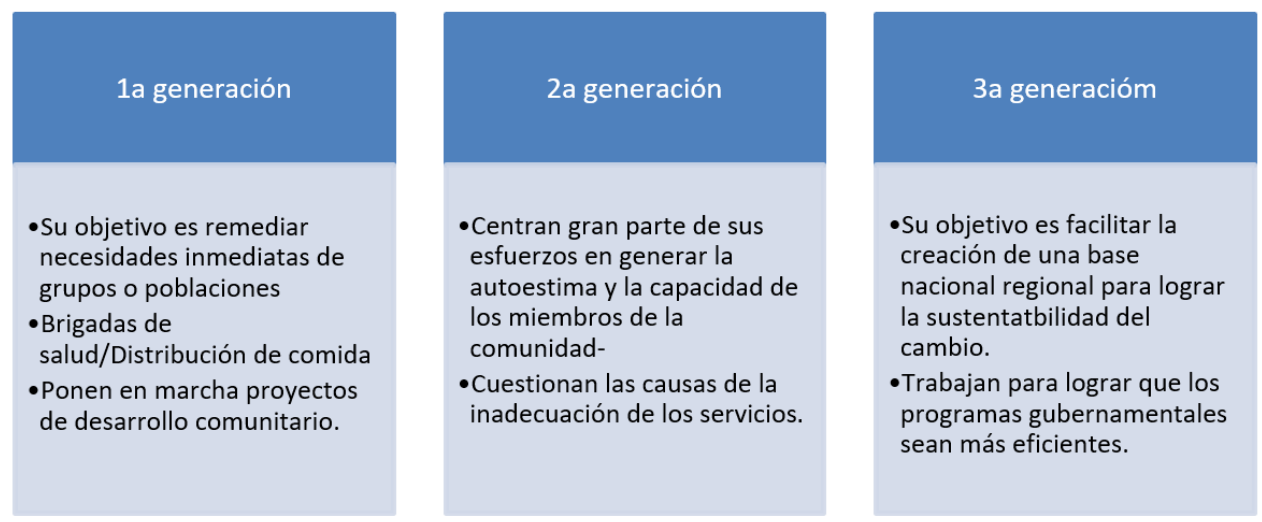

Figura 2 - Generaciones de las Organizaciones No Gubernamentales (ONG). 
radio, televisión e impresos.

\section{Las problemáticas sociales en el contexto actual internacional}

El 12 de agosto del 2015 se aprobó en la Asamblea General de las Naciones Unidas en Nueva York, la agenda para el desarrollo, titulada "Transformar nuestro mundo: la Agenda 2030 para el Desarrollo Sostenible". La importancia de esta agenda internacional de compromiso político, es ser un plan de acción mundial para la gente, el planeta y la prosperidad; buscando la paz universal en alianza colaborativa en los próximos 15 años.

La relevancia de la Agenda 2030 radica en que orientará las políticas públicas, programas de desarrollo nacionales y locales, influirá en las propiedades presupuestales de países y la Cooperación Internacional, e intentará vincular una acción entre comunidad internacional, gobiernos, Organizaciones de la Sociedad Civil (OSC) y el sector privado.

Las problemáticas sociales deben de ser atendidas través de tres pilares interdependientes: lo social, lo económico y el medio ambiente. Asimismo, se han compactado en 17 objetivos cuyos principales temas son: la igualdad de género, salud, educación trabajo, energía, biodiversidad, océanos y financiamiento. En este contexto, las campañas de publicidad social tendrán que ser una herramienta de comunicación para la promoción del cambio de ideas para modificar creencias, actitudes, comportamientos y valores, para así aspirar a transformar nuestro mundo.

\section{Nuevas estrategias}

Para comprender la evolución en los últimos 60 años de la gestión de las campañas de publicidad social en México, desde la elección de los objetivos publicitarios, la construcción de los mensajes de comunicación y la selección de los medios publicitarios, es necesario partir de las siguientes premisas:

1. Las problemáticas sociales se han diversificado.

2. Existen nuevos agentes de cambio para la incidencia social.

3. Se han visibilizado nuevos grupos vulnerables.

4. Las estrategias de comunicación publicitaria requieren de una metodología más efectiva.

5. Los canales de comunicación convergen en los mundos offline y online.

Se retomaron en este análisis los elementos centrales de una campaña de cambio social que proponen Kotler \& Roberto (1993):

- Causa. Un objetivo social que los agentes de cambio creen que ofrecerá una respuesta conveniente a un problema social.

- Agente de cambio. Un individuo, organización o alianza que intenta generar un cambio social y lo que implica una campaña de cambio social. 
- Destinatarios. Individuos, grupos o poblaciones enteras que son el objetivo de los llamados al cambio por el comercializador social.

- Canales. Vías de comunicación y distribución a lo largo de los cuales se intercambian y transmiten hacia atrás y hacia delante la influencia y respuesta entre los agentes de cambio y los destinatarios.

- Estrategias de cambio. La dirección y el programa adoptados por un agente de cambio para llevar a cabo el cambio en las actitudes y conducta de los destinatarios.

\section{Análisis de casos}

Campaña: Perrea un libro.

Año: 2015.

País: México.

Causa: Promoción de la lectura.

Agente de Cambio: Instituto de Investigaciones Filológicas de la Universidad Nacional Autónoma de México (UNAM). Academia.

Destinatarios: Jóvenes menores de 30 años.

\section{Estrategia:}

Objetivo. Acercar a los jóvenes a la lectura a través del reggaetón.

Idea. A los jóvenes no les gusta leer, pero les gusta bailar. Partiendo de esta premisa, se tomaron textos del libro Tren Subterráneo, del escritor Fernando Curiel, para formar la letra de una canción de reggaetón producida por DJ Chango, donde se les demostró que habían empezado a leer mientras cantaban. Según información del periódico El Universal, "el video de dos minutos cuya canción fue producida con ayuda del cantante panameño Baby Killa y el productor del género musical perreo, Dj Chango, se grabó en un estudio de la delegación Iztapalapa" (AGUILAR SOSA, 2015) y se llevó a lo que parece ser una fiesta.

\section{Canales:}

1. Se realizó una activación en una fiesta en la Delegación Iztapalapa, en la que se reprodujo la cinta y se entregaron ejemplares a las y los jóvenes asistentes, mencionándoles que lo que acaban de escuchar era parte del texto que tenían en sus manos.

2. Se diseñó un video como estudio de caso, el cual se viralizó en YouTube en la categoría de Educación, para generar una discusión de la sociedad,

3. Se llevó la discusión a las redes sociales en Facebook y Twitter.

Link: https://www.youtube.com/watch?v=2CneSfzi3Lg

Campaña: \#No es de hombres

Año: 2017

País: México

Causa: Hostigamiento y acoso sexual hacia las mujeres. 
Agente de Cambio: ONU mujeres (Organismo Internacional)

Destinatarios: Hombres que hostigan y acosan sexualmente a las mujeres en el metro de la CDMX

\section{Estrategia:}

Objetivo. Denunciar y retratar el hostigamiento que sufren las mujeres por parte de los varones en el metro de la CDMX.

Idea. Se realizaron dos experimentos sociales. En el primero se utilizó un asiento en un vagón de uno de los trenes del Sistema de Transporte Colectivo Metro, línea 7 (El Rosario - Barranca del Muerto), el cual se diseñó "exclusivo para hombres".

El lugar fue intervenido por los creadores de la campaña, ya que el respaldo simulaba el torso de un hombre y en la parte inferior un pene, haciéndolos sentir incómodos al sentarse, con lo que ejemplifican los llamados arrimones que sufren las mujeres. En un letrero colocado frente al asiento se lee: Es molesto viajar aquí, pero no se compara con la violencia sexual que sufren las mujeres en sus traslados cotidianos. (VALDÉZ, 2017)

En el segundo experimento las pantallas en el andén de la estación Auditorio de la misma línea, se utilizaron para proyectar imágenes de las nalgas de los hombres que esperaban la llegada del tren. Al final de las secuencias apareció la leyenda "Esto lo sufren miles de mujeres todos los días".

\section{Canales:}

1. Publicidad de guerrilla en la que se intervino un vagón del metro de la CDMX.

2. Publicidad de guerrilla en el andén haciendo uso de las pantallas de espera.

3. Elaboración de un video de estudio de caso, el cual se viralizó en la redes sociales como Twitter y YouTube.

Links:

https://www.youtube.com/watch?v=9-yTh5_16FY\&pbjreload=10

https://www.youtube.com/watch?v=jvebzl_egJc\&pbjreload=10

Campaña: Hair fest.

Año: 2014.

País: México.

Causa: Donación de cabello para niños con cáncer.

Agente de Cambio: Casa de la amistad (Organización Civil).

Destinatarios: Niños con cáncer.

\section{Estrategia:}

Objetivo. Diseñar el primer festival en donde el boleto de entrada es el pelo. Idea. The Hair Fest fue el primer festival de rock en el mundo en donde el boleto de entrada era un mechón de cabello de los asistentes. Recordemos que durante un tratamiento contra el cáncer, el contar con pelucas ayuda a reforzar la autoestima de los niños.

El evento constó de 9 bandas mexicanas, 8 horas de metal, cabello de más de 100 metaleros para realizar 107 pelucas, el equivalente a 1 año de donaciones o $\$ 160,500$ USD. Además, se obtuvieron $\$ 500,000$ USD en publicidad gratuita y 9 
millones de vistas en redes sociales.

\section{Canales:}

1. Difusión del evento en redes sociales

2. Evento de mercadotecnia en beneficio de los niños con cáncer de Casa de la Amistad.

3. Elaboración de un video de estudio de caso sobre el desarrollo de toda la estrategia el cual se viralizó en las redes sociales como YouTube y en las páginas de la Agencia Ogilvy de Casa de la Amistad.

Link: https://www.youtube.com/watch?v=fhdMAPepJ5g\&pbjreload=10

\section{Recapitulando}

Considerando las cinco premisas para entender la forma en la que hoy se diseñan las campañas publicitarias sociales en México y como han ido evolucionando a través de los años, se pueden llegar a las siguientes conclusiones:

Las problemáticas sociales se han diversificado.

Gracias a la evolución de las Tecnologías de la Información y la Comunicación y la globalización, actualmente las problemáticas sociales atañen al mundo entero. Las agendas internacionales empiezan a confluir en objetivos mundiales. Antes de la Agenda 2030, los Objetivos de Desarrollo del Milenio (ODM), fueron consensuados en el año 2000 por los 189 países miembros de las Naciones Unidas, objetivos que deberían cumplir en metas mensurables y con plazos definidos para combatir la pobreza, el hambre, las enfermedades como el VIH y la malaria, la sostenibilidad del medio ambiente, la educación y la igualdad de género.

Estas agendas son un reflejo de las necesidades de atender problemáticas cada vez más específicas en diferentes esferas del ser humano. Hoy por ejemplo, se puede hablar de diferentes tipos de violencia como: Violencia de género, violencia en el noviazgo, violencia sexual, hostigamiento, acoso callejero, feminicidos, etc.

\section{Existen nuevos agentes de cambio para la incidencia social.}

Actualmente ubicamos a las Organizaciones de la Sociedad Civil (OSC), el sector privado, la academia y organismos internacionales como creadoras de campañas de publicidad social.

Las agencias del Sistema de las Naciones Unidas en México, sirven de puente entre México y el mundo, a través del intercambio de experiencias y de buenas prácticas para el desarrollo, además de trabajar de manera conjunta en colaboración técnica con gobiernos federal y locales, academia, sector privado y sociedad civil. En muchos de estos proyectos las campañas de publicidad social o experimentos sociales coadyuvan en la reducción de las causas sociales que cada agencia abandera.

Por su parte, la academia como se pudo analizar en el caso de la Universidad Nacional Autónoma de México (UNAM), ha hecho esfuerzos que suman para visibilizar las realidades sociales que se viven en todo el país. Finalmente, la iniciativa privada 
es quizás uno de los principales agentes de cambio con mayor presupuesto y creatividad al momento de realizar campañas sociales. No obstante, vale la pena detenerse a analizar las estrategias de mercadotecnia que hay detrás de los mensajes; sobre todo en la credibilidad de los mismos acorde a los objetivos que persiguen las marcas y los beneficios que se esperan alcanzar en los públicos objetivos.

Se han visibilizado nuevos grupos vulnerables.

La diversificación de las causas sociales ha permitido visibilizar las realidades sociales que viven diversos grupos. A diferencia de la publicidad comercial que llega a targets bien definidos, en las campañas de índole social es prudente considerar a los públicos beneficiarios, afligidos y negativos; pues todos ellos desempeñan un rol importante para generar un cambio y sólo así poder verdaderamente transformar nuestro mundo. Más allá de pensar en una lógica de consumidores que adquirirán un bien, producto o servicio, se deben pensar en personas que busquen un bien común.

- La población negativa está conformada por personas necias y reacias, que muestran un rechazo alguno ante alguna causa social por motivos culturales, sociales o de mera contradicción.

- La población afligida son aquellas personas que padecen alguna situación crítica y muestran un comportamiento donde ven riesgos significativos, piensan mucho antes de actuar y buscan casi siempre el consejo de los demás.

- La población beneficiaria son ese sector que necesita resignificar algún comportamiento, actitud o creencia para poder emancipar alguna práctica nociva en su entorno. Es mucho más difícil motivar a la gente para que emprenda acciones cuando no son ellos los beneficiados de manera directa, familiares o seres más cercanos.

Las estrategias de comunicación publicitaria requieren de una metodología más efectiva.

Usando como base la definición de Kotler \& Roberto (1993), consideramos la publicidad social como un proceso de comunicación, gestionado por un agente de cambio que puede ser del sector público, privado, académico, organismos internacionales o del tercer sector, en la que se pretende incidir en grupos sociales vulnerables para aceptar o modificar ideas, creencias, actitudes, comportamientos, hábitos, costumbres y valores que atañen a las diferentes realidades sociales, en busca de un bienestar social.

Actualmente para diseñar campañas de publicidad social efectivas, deben de entenderse los problemas sociales que hoy nos preocupan desde una perspectiva multifactorial, que atañen a diferentes sectores (salud, educación, población, etc.) y en diferentes dimensiones (sociales, económicas y ambientales).

Por ello, las campañas de comunicación publicitaria deben de considerar los siguientes elementos:

Causa 
- Delimitación del problema.

- Identificación de las principales causas que originan ese problema.

- Indicadores de problemática actual basados en datos duros de estudios, encuestas e investigaciones académicas y gubernamentales.

- Beneficios que trae consigo atender la problemática.

Agente de cambio

- Corazón ideológico (misión, visión, filosofía y valores).

- Programas / políticas públicas en las que se sustenta su problemática.

- Vinculación con otros agentes de cambio como organismos internacionales, organizaciones de la sociedad civil, instituciones de gobierno, academia y/o iniciativa privada.

- Antecedentes publicitarios de los últimos 3 años.

Destinatarios

- Segmentación demográfica.

- Segmentación socioeconómica.

- Segmentación psico-conductual que incluya barreras, resistencias, creencias, actitudes, comportamientos, hábitos, valores, objetivos, necesidades y deseos.

- Justificación del porque es el público beneficiario de las acciones.

- Descripción de posibles públicos negativos y/o afligidos.

\section{Estrategias}

- Elección y justificación de un tipo de campaña a cumplir.

- Desarrollo de una estrategia creativa que contemple un concepto creativo original basado en insights

- Diseño de una estrategia con un enfoque de derechos humanos y perspectiva de género cuando se trate de de probelmas sociales.

- Elaboración de mensajes con un enfoque emocioanl y experiencial que narren historias para conmover y llamar a la acción.

\section{Canales}

- Diseño de una estrategia de medios justificando los hábitos mediáticos del público beneficiario.

- Elaboración de un plan de medios que haga sinergia en los diferentes medios publicitarios, estrategias de mercadotecnia (digital, promocional, viral, etc...) y otros esfuerzos de comunicación (relaciones públicas, promociones, etc..)

Los canales de comunicación convergen en los mundos offline y online.

El alcance de las campañas publicitarias sociales es limitado, ayudando a visibilizar tanto las causas como grupos vulnerables. No obstante, debe apoyarse de otros de comunicación y de mercadotecnia para lograr un mayor impacto. De ser así, al final el proyecto se convierte en un reto de tocar fibras para hacer conciencia, y después generar una acción por un cambio social verdadero.

Los medios se han diversificado a tal punto que se puede hablar de comunica- 
ciones integradas que convergen tanto en el mundo offline como el mundo online. Ejemplo de ello se puede observar en acciones como:

- El diseño de estrategias digitales que requieren del uso de dispositivos móviles.

- La creación de contenidos en formato de imágenes, videos y texto a través de las principales redes sociales como Instagram, YouTube, Facebook y Twitter.

- La elaboración de experimentos sociales que se hacen virales a través de las redes sociales.

- Gestión de estrategias de guerrilla, consideradas campañas publicitarias no tradicionales.

Finalmente consideramos trascendente, desde la academia, revisar el pasado, los aciertos y las áreas de oportunidad de la publicidad social en México para que las futuras propuestas se adapten a nuevas realidades, diferentes público y medios; consolidar una publicidad social en constante evolución que impacte y logre el cambio deseado.

\section{Referências}

\section{Libros}

CNP. Compromiso con México. México: CNP, 2002.

GANDOLFO, J. La publicidad de bien público. Buenos Aires, 2012.

GONZÁLEZ, S. Prensa y poder político: la elección presidencial de 1940 en la prensa mexicana. México: Siglo XXI, 2006

KOTLER, P., \& Roberto, E. Marketing social: estrategias para cambiar la conducta pública. México: Diana, 1993.

REYGADAS Robles, G. R. Abriendo veredas: iniciativas publicas y sociales de las redes de organizaciones civiles. México, 1998.

TORRES, B. Las Organizaciones No Gubernamentales: avances de investigación sobre sus características y actuación. En E. J. (coord.), Organizaciones civiles y políticas públicas en México y Centroamérica (pág. 42). México: Miguel Ángel Porrúa, 1998.

\section{Artículos}

SOSA Hernández, G. Georgina. (2010). El Consejo de la Comunicación: "Portavoz" de los empresarios en la democracia mexicana. Andamios, 7(14), 69-99. Disponible en: http://www. scielo.org.mx/scielo.php?script=sci_arttext\&pid=S1870-00632010000300004\&lng=es\&tlng=es SOSA Hernández, G. Georgina. (2016). El Consejo Nacional de la Publicidad (CNP). La "voz" empresarial mexicana en tiempos no democráticos (1959-2000). Secuencia, (95), 115-151. https://dx.doi.org/10.18234/secuencia.v0i95.1380

Tesis

LIZCANO Álvarez, G.; Sánchez Islas, L. La publicidad social en México: recuento de 50 años. 
Licenciatura. Universidad Nacional Autónoma de México, Facultad de Ciencias Políticas y Sociales, 2003.

\section{Notas peridísticas}

Aguilar Sosa, Y. (08 de 04 de 2015). UNAM le entra al "perreo" con literatura. El Universal. Disponible en: http://www.eluniversal.com.mx/articulo/cultura/letras/2015/04/8/unam-leentra-al-perreo-con-literatura.

Excelsior. (25 de Nov de 1959). Una de las ideas más generosas y patrióticas. Excelsior, pág. 14. Valdéz, I. (24 de 03 de 2017). Campaña de ONU mujeres contra el acoso en el Metro. El Milenio. Disponible en: http://www.milenio.com/region/campana-onu_mujeres-acoso_ metro-violencia_sexual-transporte-agresiones-cdmx-milenio_0_925707442.html 


\section{Social advertising in Mexico, understand your past and create your future}

\section{Abstract}

The main objective of social advertising is the change of behavior or attitude for social welfare; therefore, in this work we consider of great interest, to review the historical development of this form of advertising in Mexico from the Lázaro Cárdenas regime (1934-1940) to the present, showing the changes in the campaigns, their causes, factors of change, receivers and distribution channels. The result of the analysis illustrates the evolution of social advertising in Mexico and the aspects related to the political and economic development in the country, from ideological objectives and local social problems, to global crisis and digital media.

\section{Keywords}

Social Advertising. History. Transition. Mexico.

\section{Sobre os autores}

Docente e investigador en publicidad en Facultad de Ciencias Políticas y Sociales, UNAM. eeta_sigma@hotmail.com

Liliana Andrea Sánchez Islas. Departamento de Bibliografía Latinoamericana, Dirección General de Bibliotecas (DGB), Universidad Nacional Autónoma de México (UNAM), México, D.F. Licenciada en Ciencias de la Comunicación y maestra en Comunicación por la UNAM. Editora asociada de Latindex, analista de información para la base de datos Clase y docente en la Facultad de Ciencias Políticas y Sociales (FCPyS) de la UNAM. 